Check for updates

The BMJ

Cite this as: $B M / 2022 ; 376: 0350$ http://dx.doi.org/10.1136/bmj.0350 Published: 11 February 2022

\title{
Covid-19: Staff absences are continuing to stretch NHS hospitals, say leaders
}

\section{Gareth lacobucci}

Staff absences due to covid-19 are continuing to place acute hospital services under major pressure, medical leaders have told The BMJ.

Official data show that an average of 70 ooo hospital trust staff in England were absent from work in the week ending 30 January, 28000 (40\%) of whom were off because of covid-19. ${ }^{1}$ On 18 and 19 January The $B M J$ visited University Hospitals Coventry and Warwickshire NHS Trust (UHCW) to speak to leaders and staff about workforce pressures (video 1).

Video 1 Staffing in University Hospitals Coventry and Warwickshire NHS Trust

In the seven days to 19 January UHCW had an average of 644 staff absent, 275 (43\%) of whom were absent because of covid-19. Since then, staff absences have remained high: the latest available data for the week ending 30 January show an average of 680 staff absent, 40\% (269) from covid-19.

These numbers show a dip from the peak of the omicron variant in early January: from 3 to 9 January an average of 1000 staff were absent at the trust, $52 \%$ (515) from covid.

But leaders at the trust told The BMJ that pressures remained tangible. Kiran Patel, chief medical officer at UHCW, said, "We're quite concerned about making sure we have enough staff to run all of our services, and we are concerned because of the impact of isolation of staff who either have tested positive or their family members have tested positive for covid needing to take time off work.

"And of course, that happens in an unplanned manner, so it's a sudden loss of staffing at scale. That makes it increasingly difficult to plan and schedule services, and we're doing that on a day-by-day basis at the moment."

Ed Hartley, a consultant and clinical director for the emergency department at Coventry, said that the number of staff absent through covid had made this year much harder than previous winters.

"We are used to staff suffering from short term sickness, coughs and colds, and bugs," he told The $B M J$. "But at the moment, with covid, one case of covid in the household means that one member of staff might be off for five to seven days. It's causing us to make some real last minute changes to our rota."

\section{National pressures}

The workforce pressures are not confined to Coventry. In a survey of 1016 healthcare staff published last week by YouGov, ${ }^{2} 95 \%$ said that their workplace had recently been affected by staff shortages due to covid-19. This included nearly half (48\%) who said that their workplace had been affected to a "great" extent and $37 \%$ who said it had been affected to a "moderate" extent. Only 3\% said that they had not been affected.

Healthcare workers in NHS hospitals were the most likely to say that they had been "greatly" affected (55\%), compared with $46 \%$ in mental health trusts, $41 \%$ in community services and local authorities, and $37 \%$ at general practices.

Of the NHS staff whose workplace had been affected by staff shortages, $71 \%$ said that current staff were working overtime or doing extra shifts to make up the missing hours, $38 \%$ said that their workplace was bringing in agency staff to cope with shortages, and $36 \%$ said that staff were being redeployed from nearby locations to assist.

Some $18 \%$ said that recently retired staff had returned to work to help, while a further $9 \%$ said that their workplace was using volunteers to fill gaps.

NHS England. Covid-19 NHS \& MHLDA situation report: staff absences 29 November 2021 to 30 January 2022 (spreadsheet). Feb 2022 https://www.england.nhs.uk/statistics/wp-content/uploads/sites/2/2022/02/Staff-Absences-Web-File-Timeseries.xIsx

2 Ibbetson C. Nine in ten NHS workers say their workplace has seen staff shortages due to COVID-19. YouGov. 2 Feb 2022.

https://yougov.co.uk/topics/health/articles-reports/2022/02/02/nine-tennhs-workers-say-their-workplace-has-seen-

This article is made freely available for personal use in accordance with BMJ's website terms and conditions for the duration of the covid-19 pandemic or until otherwise determined by BMJ. You may download and print the article for any lawful, non-commercial purpose (including text and data mining) provided that all copyright notices and trade marks are retained. 